ARTIGOS

\title{
Universidade e Escola Básica: Formação inicial e continuada de professores que ensinam matemática em espaços colaborativos
}

Mercedes Carvalho

\begin{abstract}
RESUMO
Este artigo é sobre o projeto em rede Observatório da Educação, núcleo Universidade Federal de Alagoas. Durante o período de 2013 a 2016 a universidade desenvolveu trabalho colaborativo com duas escolas estaduais de educação básica, em Maceió. O grupo contou com a participação de três estudantes da licenciatura em matemática, três pedagogas: gestora, coordenadora e professora do $5^{\circ}$ ano do ensino fundamental, uma professora de matemática e uma doutoranda. Durante este período a pedagoga, docente no $5^{\circ}$ ano do ensino fundamental e a professora de matemática trabalharam em parceria objetivando favorecer a aprendizagem matemática dos alunos. Também foram desenvolvidas oficinas pedagógicas para os professores das escolas e oficinas de reforço para os alunos do $9^{\circ}$ ano do ensino fundamental e médio. A experiência se mostrou profícua para todo o grupo que buscou entender o cotidiano escolar e buscar soluções possíveis para os problemas reais da aprendizagem escolar.
\end{abstract}

\section{PALAVRAS CHAVE}

Trabalho colaborativo, ensino da matemática, grupo

\begin{abstract}
This article is about the project in network Observatory of Education, Federal University of Alagoas core (UFAL). During the period 2013-2016 the university has developed collaborative work with two state schools of basic education, in Maceió. The group with the participation of three students of the degree in mathematics, three educators: manager, coordinator and teacher of the 5th grade of elementary school, a teacher of mathematics and a PhD student. During this period, pedagogue, teaching the 5th grade of elementary school and mathematics teacher worked in partnership aiming to promote mathematics student learning. educational workshops for teachers and school reinforcement workshops for students of the 9th grade of elementary and secondary education were also developed. The experience proved fruitful for the whole group that sought to understand the school routine and seek possible solutions to the real problems of school learning.
\end{abstract}

\section{KEYWORDS}

collaborative work, mathematics teaching, group 


\section{autêntica}

\section{APRESENTAÇÃO}

Este artigo é sobre o núcleo Alagoas que fez parte do projeto em rede intitulado Trabalho colaborativo com professores que ensinam matemática na educação básica em escolas públicas das regiões Nordeste e CentroOeste, aprovado em 2012 pela Coordenação de Aperfeiçoamento de Pessoal de Nível Superior - CAPES, no programa Observatório da Educação que reúne as universidades Federal de Mato Grosso do Sul (UFMS), Estadual da Paraíba (UEPB) e Federal de Alagoas (UFAL).

Em linhas gerais, as três universidades realizaram um trabalho colaborativo envolvendo a universidade e a escola básica, momento em que, professores do ensino fundamental e médio, alunos de cursos de licenciatura em Matemática, pós-graduandos e pesquisadores trabalharam juntos (IBIAPINA, 2008) em busca de caminhos que favoreçam a aprendizagem dos conteúdos e procedimentos matemáticos na escola básica.

Cada universidade desenvolveu pesquisa atendendo às caracterísitcas regionais e linhas das respectivas pesquisadoras coordenadoras do Projeto OBEDUC. Na UFMS, o eixo norteador focaliza as práticas docentes na formação dos professores de matemática do ensino fundamental II e ensino médio. Na UEPB, o projeto desenvolveu pesquisas sobre os recursos didáticos: robótica, geogebra, educação matemática para cegos, uso da calculadora, contemplando os segmentos da Educação Básica. Na UFAL, a pesquisa objetivou, principalmente, observar a colaboração entre a pedagoga que atua no $5^{\circ}$ ano do ensino fundamental e a professora de matemática dos anos finais do ensino fundamental. A proposta desta pesquisa também agregou a figura do gestor para a ampliação das discussões realizadas no grupo de trabalho e, também, para garantir a execução do projeto na instituição escolar, já que ele é o agente "responsável (legal, judicial e pedagógico) pela escola e é o líder e articulador das ações e recursos com vistas ao bom funcionamento e aprendizagem efetiva dos alunos" (MEDEIROS et al, 2014, p. 122).

Neste artigo busco apresentar o trabalho desenvolvido nas escolas parceiras do projeto com ênfase no trabalho colaborativo dos atores participantes e os desdobramentos observados durante os três anos de sua duração.

\section{FORMAÇÃO INICIAL E CONTINUADA DE PROFESSORES DE MATEMÁTICA EM UM PROCESSO DE COLABORAÇÃO}

Formar professores com conhecimentos direcionados, tanto do conteúdo da matéria, quanto da didática do conteúdo da matéria (SHULMAM, 1986), é um dos fatores que favorece o ensino de qualidade na educação básica. No entanto, formar professores não é tarefa simples pois este profissional irá atuar, em sua maioria, em escolas com necessidades e especificidades singulares que atendem populações com características socioeconômicas diversificadas e, portanto, continuará sendo formado por meio de processos de formação continuada.

$\mathrm{Na}$ formação inicial, a maioria dos cursos de licenciatura ainda apresenta preocupação em formar o futuro docente para dominar os conteúdos matemáticos em detrimento das possibilidades de ele falar "sobre a Matemática, que saiba explorar suas ideias de múltiplas formas" (FIORENTINI e CASTRO, 2003, p. 137). Nessa direção, Ponte (2005) sugere que, a formação do professor de matemática ancorada em questões da matemática e da didática da matemática, contribuem para a formação dos professores se forem "vistas de modo mais integrado" (p.16).

Assim sendo e, fundamentada nas ideias desses pesquisadores, podemos depreender que, privilegiar tanto os conteúdos matemáticos quanto os seus procedimentos na matriz curricular dos cursos de licenciatura contribui, 


\section{autêntica}

sobremaneira, para formar professores de matemática mais preparados para a rotina da sala de aula. Contudo, sabemos que nem sempre os avanços da pesquisa coincidem com os desmembramentos das práticas formativas e, nessa direção, ao pensarmos o currículo da licenciatura em matemática precisamos estar atentos ao princípio de que as pesquisas e estudos que são divulgadas nem sempre são retas paralelas ou retas perpendiculares em que, em um determinado momento, irão cruzar em um ponto comum. Portanto, "o que se passa no campo na formação de professores (seja a inicial, a contínua ou a especializada) não depende exclusivamente das novas perspectivas e compreensões alcançadas no campo da investigação". (PONTE, 2005, p.16).

Partindo da premissa que o professor de matemática durante o exercício da sua profissão continuará se formando cabe pensar sobre as propostas de formação continuada ou em serviço que são apresentadas aos professores. Propiciar aos docentes espaços em que seja permitido a eles "apropriar-se dos seus processos de formação e dar-lhes um sentido no quadro das suas histórias de vida" (NÓVOA, 1995, p.25) é necessário, isso porque, não formamos o profissional da educação pelo acúmulo de cursos, congressos, formações, mas sim, a partir de ambientes em que ele possa pensar (ou refletir) sobre sua prática e ressignificar suas experiências e conhecimentos.

Nesta direção, trabalhar com ações que favoreçam a parceria universidade/escola, como, por exemplo, práticas colaborativas, conforme as propostas por Fiorentini (2003) e Menezes Correa (2004), ou as experiências de oficinas em uma perspectiva curricular de ensino exploratório, desenvolvidas por Ponte et al (2014) ou experiências em comunidades de aprendizagem,como sugere Fiorentini (2013) são exemplos de processos de formação continuada ou em serviço que favorecem a reflexão do professor de matemática a respeito do seu trabalho pedagógico, pois apresentam propostas alicerçadas na possibilidade de incentivá-lo a construir, reconstruir, observar, interagir, praticar, pensar, ressignificar conhecimentos e práticas matemáticas. Dessa forma, pode-se evitar que este professor no exercício de sua profissão trabalhe por tentativa e erro e assim transformar essas rotinas "em certezas profissionais, em truques do ofício, em rotinas, em modelos de gestão da classe e de transmissão da matéria" (Tardif, 2000, p. 14).

Nessa direção, o trabalho colaborativo implica na construção de parcerias viáveis em que o trabalho é gerado a partir dos problemas que os professores colocam em discussão como, também, busca superar o fosso entre teoria e prática/ universidade e escola, porque envolve professores, futuros professores e pesquisadores comprometidos em torno de uma problemática comum e o projeto Observatório da Educação é um exemplo de processo formativo porque se propõem a refletir a escola em parceria com seus atores.

\section{TRABALHO COLABORATIVO}

Ao pensar no diálogo 'escola/universidade' é salutar contemplar a participação de todos os atores envolvidos, pois é na escola que a teoria poderá ou não ganhar status e o professor, por sua vez, poderá contribuir com o seu conhecimento.

Também, nessa perspectiva e pensando nos saberes docentes (Tardif, 2000, 2002), o professor tem uma história de vida profissional que possibilita tentarmos entender como ele constrói seu saber buscando desvelar suas histórias e suas práticas. Assim, aproximar o futuro professor da escola em um contexto diferente do estágio em que eles são participes

[...]amplia as possibilidades de os professores conhecerem formalmente os significados internalizados, confrontá-los e reconstruí-los por meio de um processo reflexivo que permite a tomada 


\section{autêntica}

de consciência dos conhecimentos que já foram internalizados e a consequente redefinição e reorientação dos conceitos e das práticas adotadas nos processos educativos por eles mediados.

(IBIAPINA, 2008, p.45)

Acreditamos que independente da área de atuação profissional as pessoas trazem marcas de histórias de vida pessoal e escolar, como crenças, ideias, expectativas e valores. Nessa direção, Nóvoa (1995), discute a formação de professores à luz de três diferentes dimensões: o desenvolvimento pessoal, que é produzir a vida do professor; o desenvolvimento profissional, que é produzir a profissão docente; e o desenvolvimento organizacional, que é produzir a vida na escola.

Assim, como Nóvoa (1995), também observamos que as ações implementadas pelas Secretarias de Educação, com vistas à formação continuada, são organizadas de forma individual, enfatizando o isolamento do professor e, consequentemente, não favorece o desenvolvimento profissional, reforçando a ideia de que ele é transmissor de um saber produzido no exterior de sua profissão, isto é, os professores não são vistos como produtores de conhecimento. Por conseguinte, as práticas colaborativas podem favorecer o processo de construção do coletivo na formação continuada do professor, pois propicia o desenvolvimento da autonomia docente:

\footnotetext{
A colaboração a que nos referimos, no sentido de construir conhecimento profissional coletivo, exige que se desenvolvam nessa etapa instrumentos intelectuais para facilitar as capacidades reflexivas coletivas sobre a própria prática docente, e cuja meta principal não é outra além de aprender a interpretar, compreender e refletir sobre a educação e a realidade social de forma comunitária. Instrumentos intelectuais que deveriam ser desenvolvidos com a ajuda dos companheiros, o que deveria ser facilitado por meio de mecanismos e processos de formação permanente dos professores (IMBERNÓN, 2000, p.68-69).
}

Para a escola ser vista como um espaço de formação é necessário o desenvolvimento de projetos ancorados em necessidades e desejos dos seus atores e, principalmente, manifestando "respeito aos saberes conceituais e experienciais que cada professor traz (...) bem como em relação às suas dificuldades e possíveis falhas (...) e encontrar colaborativamente soluções para os problemas" (FIORENTINI, 2010, p. 59).

Considerando a escola como espaço de colaboração e o professor como um agente desse processo, emerge a figura do gestor como catalisador de ações transformadoras. Fullan e Hargreaves (2000, p. 77), autores destacados pelos pesquisadores que discutem trabalho e pesquisa colaborativos, como também, Ibiapina (2008), Fiorentini (2010), Pereira, Lins e Carvalho (2013), advogam a cultura da colaboração porque nela todos são partícipes do processo construído ao longo do tempo.

Hargreaves (1998, p. 274), entende que é necessário reestruturar a educação redefinindo “os papéis, responsabilidades e relações entre os alunos, os professores e os líderes das nossas escolas". Assim, a colaboração é o metaparadigma da mudança educativa e organizacional da idade pós-moderna, enquanto articulador e integrador da ação, do planejamento, da cultura e da vida dos professores (ALBERTONI, 1999, p. 108).

\section{A PROPOSTA DO NÚCLEO ALAGOAS - UNIVERSIDADE FEDERAL DE ALAGOAS}

Adotando o procedimento de Carvalho (2009), Carrillo \& Climent (1999), Cunha \& Zanchet (2014) e GarciaGonzalez (2016), que usaram esquemas para apresentar suas ideias em suas respectivas pesquisas, retrato a 
dinâmica e a complexidade desse projeto, em rede, por meio de organograma para, a partir dele, desenvolver o trabalho realizado no núcleo UFAL e os produtos resultantes do trabalho.

\section{QUADRO 1- ORGANOGRAMA DO PROJETO NA UFAL}

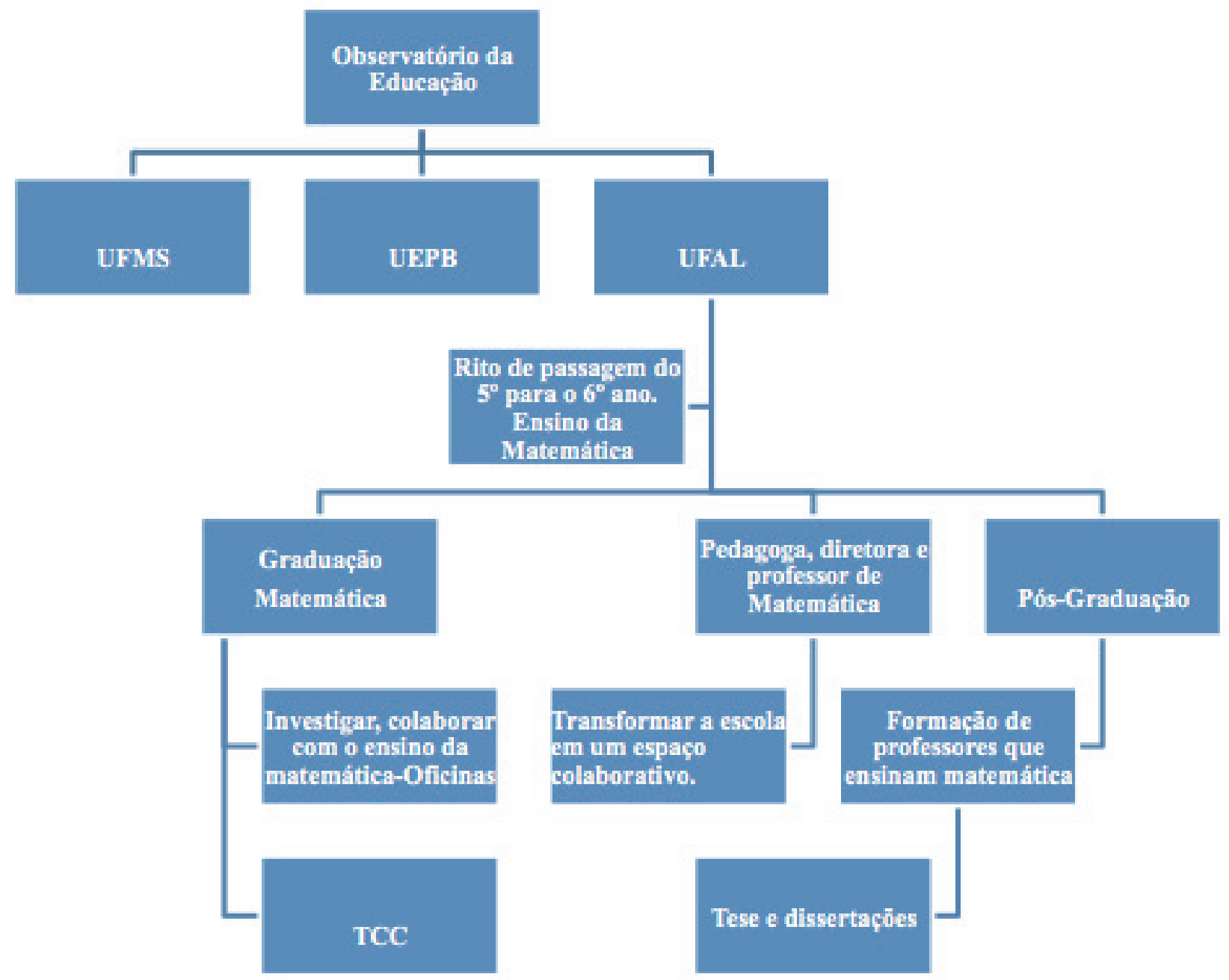

O trabalho colaborativo entre a UFAL e as duas escolas estaduais de Maceió que alicerçou todas as ações desenvolvidas nos três anos do projeto foi estruturado na colaboração do trabalho matemático entre a pedagoga que ensina Matemática no $5^{\circ}$ ano e a professora de Matemática que leciona no $6^{\circ}$ ano do Ensino Fundamental. A intenção foi observar se a proximidade dessas profissionais, em um trabalho colaborativo, contribuiu para uma melhor compreensão dos conteúdos matemáticos, por parte da pedagoga, e da metodologia para o ensino da Matemática, por parte da professora de Matemática. Cabe ainda destacar que esse procedimento metodológico e também, princípio formativo de caráter colaborativo, foi pautado nos resultados da investigação realizada no meu doutoramento, na qual aponto que 


\section{autêntica}

Também, as ações não ficaram focalizadas somente nestas duas profissionais já que o grupo incluiu a participação da gestora escolar, da coordenadora pedagógica, de três alunos da graduação em Matemática e uma doutoranda. As ações desenvolvidas ao longo de 2013/2016, além da colaboração entre a pedagoga e a professora de matemática, também resultaram em oficinas pedagógicas para os professores do ensino fundamental I e oficinas de reforço para os alunos do ensino fundamental II e ensino médio.

Realizamos o trabalho em duas escolas públicas da cidade de Maceió selecionadas por uma característica peculiar que facilitou a comunicação entre a pedagoga e a professora de Matemática, ficam na mesma rua, a uma distância de aproximadamente 500 metros uma da outra e os alunos do $5^{\circ}$ ano do ensino fundamental, egressos da Escola Estadual Jornalista Freitas Neto (ensino fundamental I), matriculam-se na Escola Estadual Guedes Nogueira (ensino fundamental II e médio) para continuidade dos estudos. Porém, até o início do presente projeto, os gestores destas escolas nunca haviam trocado informações sobre os alunos que as frequentaram. Por isso, entendo que a participação da gestão escolar favoreceu, muito, a viabilização da execução do projeto. Para Fullan e Hargreaves (2000, p. 105), "as escolas tendem a ter os líderes que merecem", isto porque, gestores que bloqueiam iniciativas docentes, que veem problemas ao invés de buscarem parcerias e soluções, acabam desencorajando os atores do processo educativo e, assim, estimulando a formação de um ambiente negativo e indiferente.

As atividades foram organizadas de acordo com o cronograma abaixo

QUADRO 2- CRONOGRAMA DE ATIVIDADES NA UFAL

\begin{tabular}{|c|c|c|c|}
\hline 2013 & 2014 & 2015 & 2016 \\
\hline $\begin{array}{l}\text { *Reunião de formação } \\
\text { do grupo para estudos } \\
\text { sobre: } \\
\text { *Pesquisa colaborativa; } \\
\text { *Currículo de } \\
\text { matemática; } \\
\text { *Formação continuada } \\
\text { e inicial de professores } \\
\text { que ensinam } \\
\text { matemática; } \\
\text { *Tecnologias } \\
\text { aplicadas ao ensino da } \\
\text { matemática. }\end{array}$ & $\begin{array}{l}\text { Início dos trabalhos } \\
\text { na sala do } 5^{\circ} \text { ano do } \\
\text { ensino fundamental. A } \\
\text { equipe acompanhará } \\
\text { o trabalho da } \\
\text { pedagoga observando } \\
\text { o desenvolvimento } \\
\text { dos conteúdos } \\
\text { matemáticos } \\
\text { e nas reuniões } \\
\text { serão discutidas } \\
\text { possibilidades de } \\
\text { trabalho para o grupo. }\end{array}$ & $\begin{array}{c}\text { Início dos trabalhos } \\
\text { na sala do } 6^{\circ} \text { ano do } \\
\text { ensino fundamental. A } \\
\text { equipe acompanhará o } \\
\text { trabalho do professor de } \\
\text { matemática e observação } \\
\text { dos processos de } \\
\text { aprendizagem dos } \\
\text { alunos egressos do } \\
5^{\circ} \text { ano da escola F1. } \\
\text { Também serão feitas } \\
\text { discussões sobre os } \\
\text { conteúdos matemáticos } \\
\text { desenvolvidos e nas } \\
\text { reuniões serão discutidas } \\
\text { possibilidades de trabalho } \\
\text { para o grupo }\end{array}$ & $\begin{array}{l}\text { Momento de finalização } \\
\text { do projeto e escrita dos } \\
\text { relatórios e artigos e } \\
\text { livros. }\end{array}$ \\
\hline
\end{tabular}

Em 2013 demos início ao trabalho e nos organizamos em sessões de estudos sobre trabalho colaborativo, currículo de matemática, aprendizagem matemática. Esses momentos forma importantes porque, além dos estudos e trocas de informações, foi o momento em que o grupo de trabalho foi se construindo. Eram profissionais convidados a participar do projeto e que atuavam em segmentos educacionais distintos e a 


\section{autêntica}

maioria não se conhecia. Para os graduandos era uma situação, totalmente, nova o que levou a pedagoga e a professora de matemática começarem, nessas reuniões, a pensar o rito de passagem dos alunos do $5^{\circ}$ ano do ensino fundamental.

Em 2014 nos encontrávamos, semanalmente, às segundas e quartas das $13 \mathrm{~h} 00$ às $15 \mathrm{~h} 00$ na Escola Freitas Neto para o trabalho de observação das aulas de matemática e, em especial, o trabalho entre a pedagoga e a professora de Matemática do $6^{\circ}$ ano. A gestora da escola organizou o horário de forma que nestes dias e horários todos os professores estivessem trabalhando matemática possibilitando, principalmente aos graduandos, observarem o conteúdo matemática desenvolvido com esse segmento de ensino.

Foi possível perceber, ainda, nos primeiros meses de trabalho em conjunto que, a pedagoga se sentia pouco confortável com a presença da professora de matemática em sua classe. Era perceptível sua preocupação com o desenvolvimento do conteúdo matemático. A professora de matemática também se mostrava desconfortável porque não entendia as dúvidas dos alunos ou porque demoravam tanto a darem uma resposta às perguntas formuladas. Essa postura era compreensível já que em sua formação inicial não Ihe foi propiciado estudar, ainda que minimamente, o conteúdo e os procedimentos matemáticos do $5^{\circ}$ ano. Entretanto, elas se reuniam, independente dos demais componentes do grupo de trabalho, para elaborarem os planos de aula, discutirem as estratégias e atividades que iriam desenvolver com os alunos e nessa colaboração foram se tornando parceiras. A pedagoga ganhou segurança em relação aos conteúdos e a professora de matemática aprendeu a dar o tempo necessário para os alunos pensarem. Ela entendeu que eles podem elaborar estratégias para os problemas que Ihes são apresentados sem, necessariamente, ser a solução esperada por ela. Como resultado, os alunos passaram a ter duas professoras a ensinar matemática.

Ainda em 2014, a gestora e a coordenadora sugeriram as oficinas pedagógicas para os professores das duas escolas a fim de trabalhar com os inúmeros jogos e materiais pedagógicos existentes na escola, que muitos professores não usavam. Este foi um momento importante para os graduandos aprenderem porque nas reuniões eles nos colocavam que observavam que as professoras sabiam lidar com os alunos, tinham boa didática, mas cometiam falhas conceituas em relação aos conteúdos matemáticos. Possivelmente essas professoras, na sua formação inicial, tiveram aulas com ênfase nos procedimentos matemáticos, em detrimento aos conteúdos, o que pode ter favorecido a reprodução da matemática que elas estudaram nas suas aulas na educação básica. Assim, nas paradas pedagógicas, organizamos oficinas em que os graduandos, a professora de matemática, a pedagoga e a doutoranda se revezaram no trabalho de sistema de numeração decimal, as quatro operações, geometria e frações utilizando jogos, materiais concretos e tablets.

Essas oficinas foram momentos importantes, em especial, para a formação dos graduandos porque tiveram a oportunidade de participarem do trabalho de formação continuada com professores do ensino fundamental. Nas reuniões em que o grupo de trabalho planejava as oficinas, os graduandos apresentavam sugestões de trabalho com os conteúdos matemáticos a partir de provas e demonstrações, uma clara evidência da característica da formação dos futuros professores de matemática em que a preocupação com o conteúdo se sobrepõe aos procedimentos matemáticos e, muitas vezes, não leva em consideração que o professor está sendo formado para lecionar na educação básica. Foi a oportunidade de conversarmos sobre o currículo de matemática na educação básica e como explorar a resolução de problemas para a aprendizagem dos alunos.

Porém, os processos de aprendizagem são endógenos e não exógenos, por isso esses graduandos, mesmo estudando e vivenciando situações diferentes do seu cotidiano acadêmico, durante a primeira oficina, ainda estavam presos aos modelos de aulas dos seus professores da graduação e neste momento havia a intervenção 


\section{autêntica}

da pedagoga e da professora de matemática exemplificando situações 'das provas e das demonstrações' o que para eles era um momento de aprendizagem, porque começavam a articular teoria e prática o que foi fundamental, pois essa experiência contribuiu para o trabalho que eles fizeram com os alunos do $9^{\circ}$ ano do ensino fundamental e ensino médio nas oficinas de reforço, pois as planejaram pautados na resolução de problemas e buscaram utilizar diferentes matérias, além do uso dos tablets.

Nesta altura do processo o grupo já estava impregnado do conceito de colaboração porque as situações observadas, individualmente, eram levadas para discussão nas reuniões e a solução era consensual. Um exemplo foi quando os graduandos, mesmo participando das atividades na escola Freitas Neto, optaram em fazer o trabalho na escola Guedes Nogueira, já que o trabalho basilar era a colaboração entre a pedagoga e a professora de matemática do $6^{\circ}$ ano. $O$ grupo concluiu que não haveria comprometimento no trabalho que estávamos desenvolvendo, pois, o projeto aprovado pela CAPES contemplou os professores de matemática na educação básica e, portanto, estávamos de acordo com o projeto que orientou os projetos nucleares.

Em 2015, a pedagoga acompanhou o trabalho da professora de matemática no $6^{\circ}$ ano e o processo fluiu seguramente porque, nesta etapa, as duas profissionais já estavam entrosadas e contavam, também com a colaboração da doutoranda, pois sua tese versa sobre o desenvolvimento profissional da pedagoga que ensina matemática em um projeto colaborativo. Os alunos, em especial, não demonstraram sentir insegurança com as aulas no $6^{\circ}$ ano do ensino fundamental, pois a maioria era egresso da escola Freitas Neto e estavam habituados a terem duas professores ensinando matemática. A pedagoga teve a oportunidade de observar quais conhecimentos matemáticos seus ex-alunos aprenderam e como os utilizavam no novo ano e a professora de matemática priorizou a resolução de problemas e, principalmente, o tempo do aluno para pensar em uma solução. Assim, as aulas ficaram mais dinâmicas e proveitosas. Cabe ainda salientar que, durante esse processo o papel da doutoranda foi significativo, pois ela promoveu a reflexão das duas profissionais, sobre as situações da sala de aula. Portanto, também tivemos um movimento de subgrupos colaborativos dentro do grupo, porque houve momentos em que todos os participantes estavam reunidos e em outros, os subgrupos (graduandos, pedagoga/professora/doutoranda, gestora) se reuniam de acordo com suas necessidades para discutirem e organizarem suas ações que eram levadas para discussão no grupo maior, revelando a autonomia que pessoas, em um processo de trabalho colaborativo, desenvolviam.

Outro momento importante para o nosso projeto foram os seminários temáticos realizados em 2013, 2014 e 2015 realizados, respectivamente, em Maceió- AL, Campina Grande- PB e Mato Grosso do Sul - MS. Esses eventos foram importantes para o amadurecimento profissional do grupo porque foi o momento de compreender que os vários problemas observados eram comuns a todos, além da oportunidade de apresentar seus trabalhos e discutir com todos os componentes do projeto.

\section{ALGUMAS CONSIDERAÇÕES SOBRE O TRABALHO COLABORATIVO}

A escola e a universidade têm tempos, espaços e objetos de estudos que se diferenciam, porém não inviabiliza ou impossibilita a colaboração mútua, pois todos buscam dar qualidade à educação básica e um caminho possível é o trabalho colaborativo porque possibilita a superação da dicotomia entre teoria e prática, pois todos são produtores de saberes e contribuem para o trabalho de qualidade. Se o professor tem compromisso com a investigação da sua prática, ou seja, estudar a sua prática pois, investigar/pesquisar demanda uma estrutura que a maioria das escolas não tem, esse cenário pode ser favorecido se a gestão escolar transformar a escola em um espaço de investigação para buscar solucionar seus problemas imediatos, como foi oportunizado nas escolas parceiras do projeto Observatório da Educação. 
Quanto aos graduandos, futuros professores de matemática, participar desta experiência sugere que, mesmo que os cursos de licenciatura estejam a buscar mudanças no seu modelo de ensino, ainda estão muito distantes da realidade da Escola e que, os estágios supervisionados obrigatórios nestes cursos não são suficientes, porque a sociedade e, consequentemente, a escola passam por processos de mudança muito mais ágil e urgente. Assim, a maioria dos cursos de Licenciatura não consegue dar vazão às reais necessidades de formação de professores para atuarem na escola, que necessita de práticas pedagógicas que deem respostas aos seus conflitos acerca do processo de ensino e aprendizagem da matemática.

Nessa direção, um caminho viável é a participação dos futuros professores em projetos como o Observatório da Educação, que atendem às políticas educacionais, como a Resolução n.2/2015 que em um dos seus artigos prevê que a formação docente "pode ocorrer em lugar similar àquele em que vai atuar" e neste projeto colaborativo é o que buscamos alcançar.

Ainda, propiciar o diálogo entre profissionais do ensino fundamental I e II aponta para uma estratégia que favorece a aprendizagem dos conteúdos e procedimentos matemáticos pelos alunos, e é possível, com custo reduzido e melhor resultado, que as coordenadorias de ensino municipais e estaduais criem espaços para formação continuada em que pedagogos e licenciados estejam juntos, dialogando sobre os processos de ensino e aprendizagem dos conteúdos matemáticos, porque essa organização fomenta a reflexão sobre as reais necessidades dos professores no cotidiano escolar como demonstrou o projeto Observatório da Educação, núcleo UFAL.

A universidade, por sua vez, pode incentivar ações que oportunizem o diálogo entre os centros de educação e as licenciaturas, já que nas universidades públicas são centros de educação responsáveis pelas matérias pedagógicas e um caminho promissor é fazer com que um dos estágios da licenciatura em matemática seja realizado no $5^{\circ}$ ano do ensino fundamental. Quanto as pesquisas realizadas pelas universidades, o projeto Observatório da Educação possibilitou fazê-las de modo mais interessante, isso porque, desenvolveu a aprendizagem em um processo de copesquisa e cotrabalho, nos permitindo estabelecer "interação com as múltiplas competências de todos os membros do projeto, no qual cada um de nós teve o mesmo tempo e oportunidade de fala" (Lins et al. 2016)

1 Comunidades de aprendizagem, de acordo com Fiorentini (2013) são espaços em que os membros da comunidade se reúnem a fim de discutir e negociar, o significado do que eles estão fazendo, dizendo, pensando e produzindo.

2 São as reuniões que acontecem bimestralmente para planejamento e é previsto no calendário letivo

3 As oficinas aconteceram em 2014 e 2015

4 O OBEDUC custeou a compra de quarenta tablets ofertados às duas escolas parceiras no projeto. 


\section{autêntica}

\section{BIBLIOGRAFIA}

ALBERTONI, M H. B. Professores em tempos de mudança resenha In: Revista Brasileira de Educação 1999, Set/Out/Nov/Dez n¹2

http://www.anped.org.br/rbe/rbedigital/rbde12/rbde12_resenhas/rbde12_resenhas_02_os_professores_em_ tempos_de_mudanca.pdf acesso dia 29 de novembro de 2013.

Carvalho, M. O ensino da Matemática nos cursos de Pedagogia. A formação do professor polivalente. São Paulo, 2009. Tese (Doutorado em Educação Matemática) - PUC-SP.

Cunha, M. I da; ZANCHET, B M B. A. Desenvolvimento profissional docente e saberes da educação superior: movimentos e tensões no espaço acadêmico. In: Revista Brasileira de Pesquisa em Formação Docente. Belo Horizonte, v. 06, n. 11, p. 11-22, ago./dez. 2014. Disponível em http://formacaodocente.autenticaeditora.com. br. Acesso em 20 de agosto de 2016.

Fiorenti, D. Learning and professional de development of the mathematics teacher in research communities. In: Sisyphus - Journal of Education. Lisboa. Instituto de Educação, UL. 2013. p.153-181

Fiorentini, D. Pesquisar práticas colaborativas ou pesquisar colaborativamente? In: BORBA, Marcelo de Carvalho; Araújo, Jussara de Loiola. Pesquisa qualitativa em Educação Matmeática. $3^{\mathrm{a}}$ ed. Belo Horizonte. Autêntica. 2010.

Fiorentini, D.; Castro, F. C. de. Tornando-se professor de Matemática: o caso de Allan em prática de ensino e estágio supervisionado. In: FIORENTINI, D. (Org.). Formação de professores de Matemática: explorando novos caminhos com outros olhares. Campinas: Mercado das Letras, 2003.

Fullan, M.; Hargreaves, A. A escola como organização aprendente: buscando uma educação de qualidade. $2^{a}$ ed. Porto Alegre: Artes Médicas. 2000.

González, E. G. Análisis de la presencia de los principios de sostenibilidad en propuestas metodológicas universitarias. Estudio de propuestas concretas en la Universidad de Cádiz. Tese de doutorado. (Didáctica de las Ciencias Experimentales)

Espanha. Universidad de Cadiz.2016. Disponível em: http://ensciencias.uab.es/thesis/view/36 Acesso em julho de 2016.

HArgreaves, A. Os professores em tempos de mudanças. OTrabalho e a Cultura dos Professores na Idade Pós-Moderna. Alfragide, Portugal: McGraw-Hill. 1998.

Ibiapina, I. M. L. de M. Pesquisa colaborativa: investigação, formação e produção de conhecimentos. Brasília: Liber Livros. 2008.

Imbernón, F. Formação docente e profissional: formar-se para a mudança e a incerteza. 6a ed. São Paulo: Cortez. 2006. 
Lins, A.F.; Pereira, P.S; Carvalho, M. Colaborative research work project with teachers who teach mathematics at basic level education in the north east and center east brazilian state schools. In: anais... $13^{\circ}$ International Congress on Mathematic Education. Hamburg, july 2016 (in press).

Menezes Correia, J. L. Investigar para ensinar matemática: Contributos de um projecto de Investigação colaborativa para o desenvolvimento profissional de professores. Dissertação de doutorado: Universidade de Lisboa. 2004

Nóvoa, Antônio (1995). O passado e o presente dos professores. In: Nóvoa, Antônio (org.). Profissão professor. Porto: Porto Editora. ( $2{ }^{\text {a }}$ edição).

Ponte, J. P. da. A formação do professor de Matemática: passado, presente e futuro, 2005. Disponível em: <http://repositorio.ul.pt/bitstream/10451/3169/1/05-Ponte\%20\%28Conf\%20P-Abrantes\%29.pdf>. Acesso em: 20 maio 2015.

; MATA-PEREIRA, J.; QUARESMA, M.; VELEZ, I. Formação de professores do $1 .{ }^{\circ}$ e $2 .{ }^{\circ}$ ciclos: articulando contextos de formação e de prática. In: PONTE, J. P. da. Práticas profissionais dos professores de Matemática. Lisboa: Universidade de Lisboa - Instituto de Educação, 2014. Disponível em: <http://www. ie.ulisboa.pt/portal/page?_pageid=406,1852906\&_dad=portal\&_schema=PORTAL>. Acesso em: 10 maio 2015.

Resolução n. 2/2015 - Diretrizes Curriculares Nacionais para a formação inicial em nível superior (cursos de licenciatura, cursos de formação pedagógica para graduados e cursos de segunda licenciatura) e para a formação continuada. Ministério da Educação. Conselho Nacional de Educação. Disponível em: http://portal. mec.gov.br/index.php?option=com_docman\&view=download\&alias=17719-res-cne-cp-002-03072015\&category_slug=julho-2015-pdf\&ltemid=30192. Acesso setembro de 2015.

SANDALO, P., LINS, Abigail; CARVALHO, M. (2013). La formación continua de professores de matemáticas através de practicas colaborativas: experiência de três universidades públicas brasileñas. In: Anais de VII Congreso Iberoamericano de Educación Matemática. Montevideo.

SHULMAN, L. S.). Those who understand: knowledge growth. Teaching Educational Researcher. 1986, v. 15, n. 2, p. 4-14.

TARDIF, M. Saberes profissionais dos professores universitários. In: Revista Brasileira de Educação. São Paulo. 2000. n. 13, p. 5-24, jan./fev./mar./abr.

Saberes docentes e formação profissional. Petrópolis: Vozes. 2002. 
